\section{Use of non-invasive ventilation to facilitate extubation in a patient with amyotrophic lateral sclerosis with hypercap- nic respiratory failure}

\author{
Montserrat Diaz-Abad, ${ }^{1}$ \\ Chandana Chauhan, 2 Denise Epps, 3 \\ James W. Russell,2,4 Justin Kwan 5 \\ 1Department of Medicine, and \\ 2Department of Neurology, University of \\ Maryland School of Medicine, \\ Baltimore, MD; 3Department of \\ Rehabilitation Services, University of \\ Maryland Medical Center Midtown \\ Campus, Baltimore, MD; ${ }^{4}$ VA Maryland \\ Health Care System, Baltimore, MD; \\ 5Department of Neurology, Temple \\ University School of Medicine, \\ Philadelphia, PA, USA
}

\begin{abstract}
We present the case of a 44-year-old man with amyotrophic lateral sclerosis (ALS) intubated for hypercapnic respiratory failure and aspiration pneumonia. The patient was successfully extubated, transitioned to non-invasive ventilation and lived at home comfortably for 17 months, with good functional status for the first year. This case highlights the potential of prolonged survival post extubation in patients with advanced ALS and respiratory failure. The patient was managed post-discharge in a multidisciplinary ALS clinic by experienced neuromuscular and pulmonary specialists.
\end{abstract}

\section{Introduction}

Amyotrophic lateral sclerosis (ALS) is a neurodegenerative disease of the upper and lower motor neurons with poor prognosis. Most patients die from respiratory failure on average 2-4 years after symptom onset. ${ }^{1}$ Non-invasive ventilation (NIV) prolongs survival in patients with ALS. ${ }^{2}$ For patients who are intubated for acute respiratory failure related to ALS, the outcome is usually death or prolonged invasive mechanical ventilation (IMV) with tracheostomy. 3

We present the case of a 44-year-old man with ALS intubated for hypercapnic respiratory failure and aspiration pneumonia. The patient was successfully eextubated, transitioned to non-invasive ventilation and lived at home comfortably for 17 months, with good functional status for the first year. This case highlights the potential of prolonged survival post extubation in patients with advanced ALS and respiratory failure. The patient was managed post-discharge in a multidisciplinary ALS clinic by experienced neuromuscular and pulmonary specialists.

\section{Case Report}

A 44-year-old man with no past medical history or regular medical care. Approximately one year prior had noticed fasciculations in the extremities followed by dysarthria and dysphagia, and six months prior, dyspnea on exertion, orthopnea and sleeping difficulties. Symptoms progressively worsened and one month before presentation there was worsening orthopnea, dysarthria, dysphagia, sialorrhea, dyspnea on exertion, fatigue, cramps and weakness, with total weight loss of approximately 100 pounds.

The patient became unresponsive one day and was admitted with hypercapnic respiratory failure and aspiration pneumonia requiring intubation. He was treated with antibiotics and extubated to continuous NIV and transferred to our center on the third day. On arrival he was reintubated due to respiratory distress and arterial blood gas (ABG) with $\mathrm{pH} 7.35, \mathrm{PaCO}_{2} 65 \mathrm{mmHg}$, $\mathrm{PaO}_{2} 75 \mathrm{mmHg}$. Computed tomography demonstrated post-obstructive consolidation and collapse of most of the right lung.

The patient was extubated 5 days later. $\mathrm{PaCO}_{2}$ remained 50-60 mm $\mathrm{Hg}$ with nocturnal and intermittent daytime NIV use. Modified barium swallow study showed severe pharyngeal stage dysphagia and silent aspiration of thick liquids, and a gastrostomy tube was placed. Electrophysiological testing showed acute and chronic denervation and reinnervation in the extremities and the patient was diagnosed with ALS. He discharged home one week post extubation.

The patient was seen one month later at the multidisciplinary ALS clinic. He was using NIV 16 hours daily and settings were comfortable. He slept well for 7 hours uninterrupted and woke up refreshed without excessive daytime sleepiness and improved fatigue. Cough was ineffective to clear secretions. Off NIV he had dyspnea walking $>1$ block, but no dyspnea with activity on NIV, and did all activities of daily living (ADLs). On exam, body mass index was $27.1 \mathrm{~kg} / \mathrm{m}^{2}$; lungs were clear with decreased breath sounds at bases; slight rapid shallow breathing pattern, mild accessory muscle
Correspondence: Montserrat Diaz-Abad, Division of Pulmonary and Critical Care Medicine, University of Maryland School of Medicine. Sleep Disorders Center, 100 North Greene Street Room 214, Baltimore, MD 21201, USA

Tel.: +1.410.7064771 - Fax: +1.410 .7060345 . E-mail:mdiaz@som.umaryland.edu

Key words: amyotrophic lateral sclerosis; non-invasive ventilation; acute respiratory failure; invasive mechanical ventilation; extubation.

Acknowledgements: the authors would like to thank the ALS Association and the MD/DC/VA Chapter for the continued support of the University of Maryland ALS Center of Excellence and our patients.

Contributions: MDA: conceptualized and drafted the initial manuscript, contributed to acquisition and interpretation of data, and critically reviewed and revised the manuscript; CC, DE, JWR: contributed to acquisition and interpretation of data, and critically reviewed and revised the manuscript; JK: contributed to conception and design, contributed to acquisition and interpretation of data, and critically reviewed and revised the manuscript.

Conflict of interest: the authors declare no potential conflict of interest.

Funding: Supported in part by Department of Veterans Affairs (Biomedical and Laboratory Research Service and Rehabilitation Research and Development, 101RX001030), Baltimore Geriatric Research, Education, and Clinical Center (GRECC), NIH NIDDK 1R01DK107007-01A1.

Received for publication: 6 March 2019. Accepted for publication: 27 May 2019.

This work is licensed under a Creative Commons Attribution NonCommercial 4.0 License (CC BY-NC 4.0).

(C) Copyright M. Diaz-Abad et al., 2019 Licensee PAGEPress, Italy

Neurology International 2019; 11:8102 doi:10.4081/ni.2019.8102

use, decreased diaphragmatic expansion, moderately weak cough and mild paradoxical breathing; normal gait; moderate dysarthria, tongue weakness and atrophy; fasciculations and distal atrophy, distal more than proximal weakness in the legs more than the arms, and hyperactive reflexes. Riluzole, baclofen, scopolamine patch, atropine drops, and mechanical insufflatorexsufflator (MI-E) for cough augmentation were prescribed.

Over the next 9 months the patient did relatively well, able to perform most ADLs. 
He travelled several times, including a sea cruise and air travel. NIV use remained around 16 hours per day and well tolerated. There was decrease in time off the ventilator without dyspnea, from $>6$ hours to 4 hours. Forced vital capacity (FVC) decreased from an initial $1.50 \mathrm{~L}(31 \%)$ to 1.15 L (24\%) and ALS Functional Rating Scale-Revised decreased from 32 to $18 / 48$. The patient noticed dyspnea with less activity and used a rolling pole to carry the ventilator when walking. There was slowly progressive weakness of arms and legs along with worsening dysarthria. Primary nutrition was through gastrostomy tube but he continued to eat mechanical soft foods and nectar thick liquids with stable weight.

NIV was delivered with a Trilogy ${ }^{\circledR}$ ventilator (Philips Respironics, Murrysville, Pennsylvania, USA) with average volumeassured pressure support with autotitrating expiratory positive airway pressure (EPAP) mode (AVAPS-AE): target tidal volume: $500 \mathrm{~mL}(7 \mathrm{~mL} / \mathrm{kg})$; respiratory rate: 15 ; pressure support range: $10-15 \mathrm{cmH}_{2} \mathrm{O}$; EPAP range: $4-6 \mathrm{cmH}_{2} \mathrm{O}$; inspiratory time: 1 sec; rise time: 3 . NIV data download (average): $100 \%$; daily use, $14.2 \mathrm{~h}$; exhaled tidal volume: $500 \mathrm{ml}$; triggered breaths: 60 $\%$; spontaneous respiratory rate: 18 ; minute ventilation: $9.5 \mathrm{~L} / \mathrm{min}$. ABG: $\mathrm{pH} 7.38$, $\mathrm{PaCO}_{2} 61 \mathrm{~mm} \mathrm{Hg}, \mathrm{PaO}_{2} 54 \mathrm{~mm} \mathrm{Hg}$. The patient preferred to have small setting adjustments at a time. Respiratory rate was increased to $16 / \mathrm{min}$ and pressure support increased to $10-20 \mathrm{~cm} \mathrm{H}_{2} \mathrm{O}$.

Three and 6 months later (13 and 16 months post-discharge) there was marked disease progression, with increasing weakness in the arms, legs and neck, and assistance was required for most ADLs. The patient could only walk unsteadily for 10 feet and a power wheelchair was prescribed. $\mathrm{He}$ required an assisted communication device for speech and nutrition was via gastrostomy tube. The patient used NIV at least 22 hours daily and had no dyspnea on NIV; he tolerated at most 45 minutes off. With the increased use he developed nasal congestion and rhinorrhea, along with nasal bridge ulceration from mask pressure. $\mathrm{He}$ had stopped using the NIV heated humidifier and was using only one full-face mask. After a new mask fitting, he got a different full-face mask which he alternated for a few hours daily with a nasal mask and a nasal pillows mask. Nasal bridge ulceration resolved with mask rotation and nasal symptoms resolved by restarting heated humidification. FVC was $0.84 \mathrm{~L}(17 \%)$ ABG: $\mathrm{pH} 7.33, \mathrm{PaCO}_{2} 65$ mm Hg, $\mathrm{PaO}_{2} 71$ $\mathrm{mm} \mathrm{Hg}$ on the penultimate visit and target tidal volume was increased to $540 \mathrm{ml}$. On the last visit $\mathrm{PCO}_{2}$ was $58 \mathrm{~mm} \mathrm{Hg}$ and res- piratory rate was increased to 18 and pressure support to $12-22 \mathrm{~cm} \mathrm{H}_{2} \mathrm{O}$. Two weeks later the patient developed increasing dyspnea and lethargy and was admitted with hypercapnic respiratory failure and pneumonia requiring intubation. He stabilized, underwent tracheostomy and remained on IMV.

\section{Discussion}

We present the case of a 44-year-old man with advanced ALS who survived for 17 months at home on NIV after intubation for hypercapnic respiratory failure and aspiration pneumonia. The patient maintained good functional status for the majority of his time at home and derived great symptomatic benefit from NIV. This case highlights the possibility of prolonged survival at home post extubation with transition to NIV in patients with advanced ALS.

Most patients with ALS die from respiratory failure ${ }^{1}$ and NIV prolongs survival, improves quality of life and is preferred over IMV.1,2 For patients intubated for acute respiratory failure related to ALS, the outcome is usually death or prolonged IMV with tracheostomy. ${ }^{3}$ However, a small minority of patients may be transitioned to NIV after intubation and even tracheostomy, and weaning can be considered in selected patients, as some may improve after the critical phase is over.3,4-9 Associated conditions and infections should be treated, assisted cough therapy should be provided, and nutrition and medications addressed. ${ }^{6}$ To our knowledge, there has been no reported case of successful weaning from IMV to NIV with tolerance on prolonged almost continuous/continuous NIV in a patient with ALS and severe bulbar dysfunction.

Our patient was almost completely dependent on NIV for more than six months. Although infrequent, there have been reports of patients with ALS on prolonged almost continuous/continuous NIV, some cases even with moderate to severe bulbar dysfunction, although not post IMV. Smaller reports included 1 patient, 10,112 patients, 12 and then 3 patients who refused tracheostomy and survived on $24 \mathrm{~h}$ NIV for 15 to 27 months. ${ }^{13}$ Larger groups included 15 patients requiring NIV for 20-24 hours, 14 27 patients on $24 \mathrm{~h} \mathrm{NIV,15}$ and 31 patients on $24 \mathrm{~h}$ NIV with daytime mouthpiece ventilation. 8

The patient was able to tolerate almost continuous NIV despite severe bulbar involvement. Although ALS patients with moderate or severe bulbar symptoms are more likely to be intolerant of NIV, many tolerate and benefit from NIV and should be offered this therapy. ${ }^{2}$ A few patients with severe bulbar involvement successfully weaned from IMV with tracheostomy and transitioned to NIV. ${ }^{6}$ Survival post extubation in our patient was 17 months, which is longer than reported on previously undiagnosed patients weaned from IMV to NIV. 6

The patient was managed in a multidisciplinary ALS clinic post-discharge. Care in multidisciplinary ALS clinics decreases complications and improves survival and quality of life. ${ }^{1}$ Protocolized management including cough augmentation ${ }^{13}$ and monitoring by pulmonologists is key to the management of ALS and prolongs survival in patients with respiratory failure requiring NIV. ${ }^{16}$ NIV settings were adjusted regularly based on NIV tolerance, patient preference and arterial blood gases.

There was marked improvement in sleep quality with resolution of orthopnea with NIV in this patient. Poor sleep quality is frequent in patients with ALS, 17 and daytime sleepiness and sleep quality have been shown to improve significantly with NIV. ${ }^{18}$ Although the patient experienced progressive weakness and loss of independence, ${ }^{1}$ he had good quality of life on NIV after the acute respiratory failure episode.?

Volume-assured pressure support (VAPS) is a hybrid NIV mode that uses bilevel positive airway pressure (BPAP) to provide a consistent tidal volume. In AVAPS-AE a target tidal volume, autotitrating EPAP and backup respiratory rate are set, along with pressure support levels that adjust within a range to maintain a consistent tidal volume. ${ }^{19}$ VAPS can maintain a stable minute ventilation long term with few adjustments in ALS despite marked disease progression. ${ }^{20}$

The patient developed skin pressure abrasions and rhinitis during NIV therapy. Mask-related problems such as these along with mask discomfort and air leakage are the most common side effects of positive airway pressure (PAP) therapy, and are important to identify and address promptly. ${ }^{2}$ Patients need education on the importance of an appropriately fitted mask to prevent skin abrasion and air leakage, and to rotate pressure points by alternating different masks, ${ }^{10,15}$ with the increasing NIV dependence that will occur. $3,20,15$ Additionally, heated humidification helps reduce the nasal side effects of NIV, and weight loss may also affect facial contour and lead to new or increasing mask leaks and intolerance. ${ }^{20}$ 


\section{Conclusions}

Transitioning from IMV to NIV after an episode of hypercapnic respiratory failure in advanced ALS should be considered in selected patients as prolonged survival on home NIV is feasible. Serial follow-up in a multidisciplinary clinic allows for monitoring of NIV tolerance, settings adjustments and addressing treatment related sideeffects.

\section{References}

1. Andersen PM, Abrahams S, Borasio GD, et al. EFNS guidelines on the clinical management of amyotrophic lateral sclerosis (MALS)--revised report of an EFNS task force. Eur J Neurol 2012;19:360-75.

2. Aboussouan LS, Khan SU, Meeker DP, et al. Effect of noninvasive positivepressure ventilation on survival in amyotrophic lateral sclerosis. Ann Intern Med 1997;127:450-3.

3. Bradley MD, Orrell RW, Clarke J, el al. Outcome of ventilatory support for acute respiratory failure in motor neurone disease. J Neurol Neurosurg Psychiatry 2002;72:752-6.

4. de Carvalho M, Matias T, Coelho F, et al. Motor neuron disease presenting with respiratory failure. J Neurol Sci 1996;139:117-22.

5. Shoesmith CL, Findlater K, Rowe A, Strong MJ. Prognosis of amyotrophic lateral sclerosis with respiratory onset. J Neurol Neurosurg Psychiatry 2007;78:629-31.

6. Chadwick R, Nadig V, Oscroft NS, et al. Weaning from prolonged invasive ventilation in motor neuron disease: analysis of outcomes and survival. J Neurol Neurosurg Psychiatry 2011;82:643-5.

7. Oh H, Kang SW, Choi WA, et al. Motor neuron disease presenting with acute respiratory failure: A case study. Ann Rehabil Med 2017;41:328-31.

8. Bédard ME, McKim DA. Daytime mouthpiece for continuous noninvasive ventilation in individuals with amyotrophic lateral sclerosis. Respir Care 2016;61:1341-8.

9. Bach JR, Gonçalves MR, Hamdani I, Winck JC. Extubation of patients with neuromuscular weakness: a new man- agement paradigm. Chest 2010;137:1033-9.

10. Servera E, Sancho J, Gómez-Merino E, et al. Non-invasive management of an acute chest infection for a patient with ALS. J Neurol Sci 2003;209:111-3.

11. Belchior I, Gonçalves MR, Winck JC. Continuous noninvasive ventilation delivered by a novel total face mask: a case series report. Respir Care 2012;57:449-53.

12. Bach JR, Alba AS, Saporito LR. Intermittent positive pressure ventilation via the mouth as an alternative to tracheostomy for 257 ventilator users. Chest 1993;103:174-82.

13. De Vito EL, Suárez AA, Monteiro SG. The use of full-setting non-invasive ventilation in the home care of people with amyotrophic lateral sclerosismotor neuron disease with end-stage respiratory muscle failure: a case series. J Med Case Rep 2012;6:42.

14. Cazzolli PA, Oppenheimer EA. Home mechanical ventilation for amyotrophic lateral sclerosis: nasal compared to tracheostomy-intermittent positive pressure ventilation. J Neurol Sci 1996;139: 123-8. 